\title{
Review
}

\section{Beyond membrane channelopathies: alternative mechanisms underlying complex human disease}

\author{
Konstantinos Dean BOUDOULAS ${ }^{1,2, *}$, Peter J MOHLER ${ }^{1,2,3}$ \\ ${ }^{1}$ The Dorothy M Davis Heart and Lung Research Institute; ${ }^{2}$ Departments of Internal Medicine (Cardiovascular Medicine); ${ }^{3}$ Physiology \\ and Cell Biology; the Ohio State University Medical Center, Columbus, OH 43210, USA
}

Over the past fifteen years, our understanding of the molecular mechanisms underlying human disease has flourished in large part due to the discovery of gene mutations linked with membrane ion channels and transporters. In fact, ion channel defects ("channelopathies" - the focus of this review series) have been associated with a spectrum of serious human disease phenotypes including cystic fibrosis, cardiac arrhythmia, diabetes, skeletal muscle defects, and neurological disorders. However, we now know that human disease, particularly excitable cell disease, may be caused by defects in non-ion channel polypeptides including in cellular components residing well beneath the plasma membrane. For example, over the past few years, a new class of potentially fatal cardiac arrhythmias has been linked with cytoplasmic proteins that include sub-membrane adapters such as ankyrin-B (ANK2), ankyrin-G (ANK3), and alpha-1 syntrophin, membrane coat proteins including caveolin-3 (CAV3), signaling platforms including yotiao (AKAP9), and cardiac enzymes (GPD1L). The focus of this review is to detail the exciting role of lamins, yet another class of gene products that have provided elegant new insight into human disease.

Keywords: arrhythmia; channelopathy; heart disease; lamin; laminopathy; emerin; nesprin

Acta Pharmacologica Sinica (2011) 32: 798-804; doi: 10.1038/aps.2011.34

\section{Introduction}

In fact, ion channel defects ("channelopathies" - the focus of this review series) have been associated with a spectrum of serious human disease phenotypes including cystic fibrosis, cardiac arrhythmia, diabetes, skeletal muscle defects, and neurological disorders. However, we now know that human disease, particularly excitable cell disease, may be caused by defects in non-ion channel polypeptides including in cellular components residing well beneath the plasma membrane. For example, over the past few years, a new class of potentially fatal cardiac arrhythmias has been linked with cytoplasmic proteins that include sub-membrane adapters such as ankyrinB (ANK2 $)^{[1-5]}$, ankyrin-G $(A N K 3)^{[6-8]}$, and alpha-1 syntrophin ${ }^{[9]}$, membrane coat proteins including caveolin-3 $(C A V 3)^{[10]}$, signaling platforms including yotiao $(A K A P 9)^{[11,12]}$, and cardiac enzymes $(G P D 1 L)^{[13]}$. The focus of this review is to detail the exciting role of lamins, yet another class of gene products that have provided elegant new insight into human disease.

\footnotetext{
* To whom correspondence should be addressed.

E-mail Konstantinos.boudoulas@osumc.edu (Konstantinos Dean BOUDOULAS).

Received 2011-03-01 Accepted 2011-03-22
}

\section{Lamins: critical intermediate filament components}

Lamins are intermediate filament proteins and a major component of the nuclear lamina, a proteinaceous layer underlying the inner nuclear membrane, separating the nuclear envelope from the nuclear matrix. Lamins interact with proteins and chromatin, thus playing an important role in maintaining cell structure and cell regulation including apoptosis ${ }^{[14-17]}$. Lamin is involved in DNA repair and replication, transcriptional regulation, and maintaining the organization and structure of heterochromatin, nuclear lamina, inner nuclear membrane and nuclear pore complexes ${ }^{[14-19]}$. Further, lamin has been implicated to be involved in tumorigenesis and viral infections ${ }^{[18,20,21]}$.

Lamins are divided into two groups originally based on isoelectric points observed by two-dimensional gel electrophoresis: A-type lamins (almost neutral isoelectric point) and B-type lamins (acidic isoelectric point) ${ }^{[22,23]}$. A-type lamins are primarily located in differentiated cells while B-type lamins are located in all cells. Lamins have a conservative alpha helical central rod domain with an amino terminal globular head domain and carboxyl terminal globular tail domain ${ }^{[21]}$. The lamin tail domain contains an approximate 120-residue immunoglobulin fold, CAAX motif (except lamin C as described below) and a nuclear localization signal ${ }^{[24]}$. 


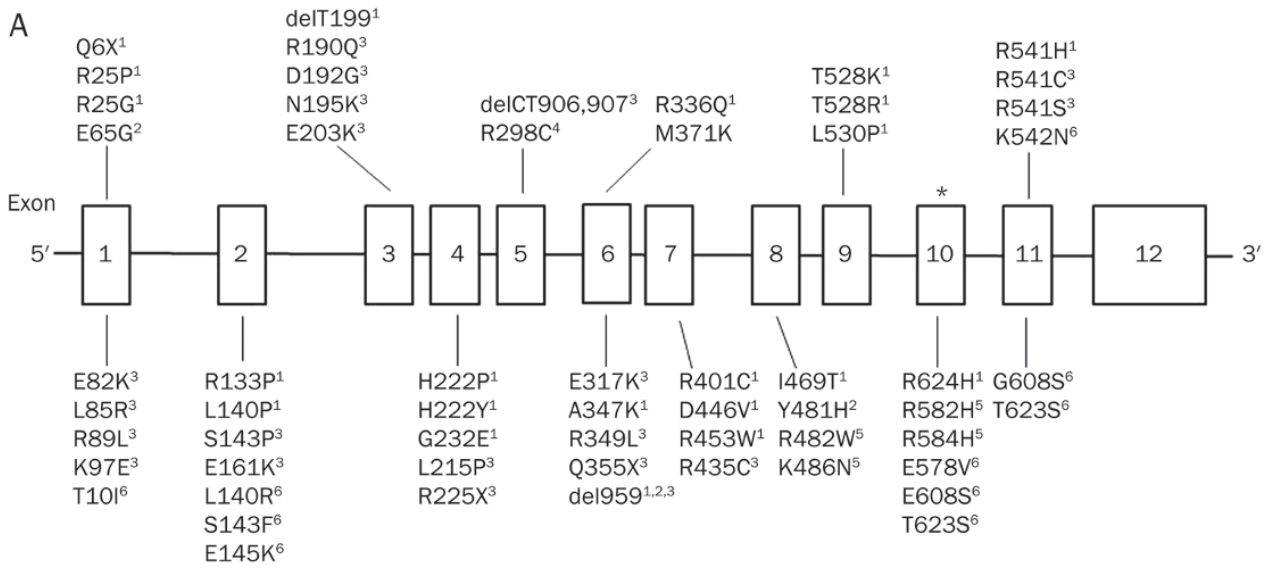

B

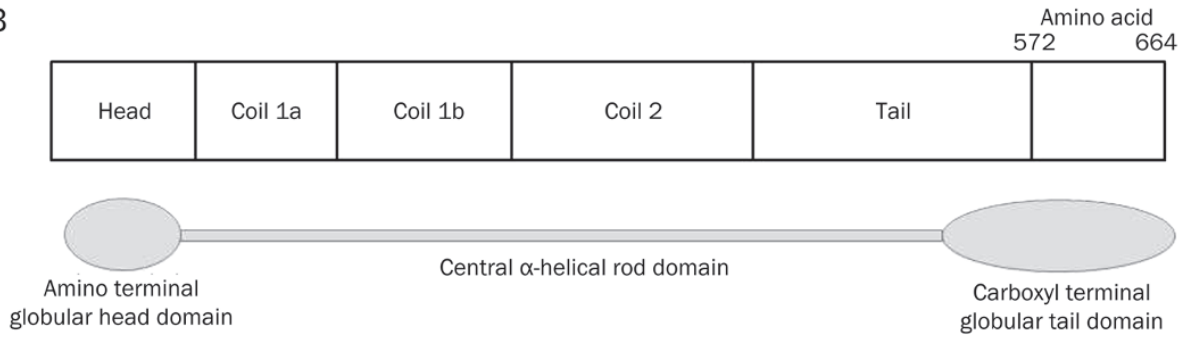

Figure 1. Schematic of (A) lamin gene (LMNA) and (B) lamin A/C protein. * indicates alternate splicing in exon 10 giving rise to the proteins lamin A (664 amino acids) and lamin C (572 amino acids). Shown are several mutations known to result in laminopathies with corresponding amino acid or nucleotide changes. 1=Emery-Dreifuss muscular dystrophy; $2=$ Limb girdle muscular dystrophy type 1B; $3=$ dilated cardiomyopathy; $4=$ Charcot-Marie Tooth type 2B1; $5=$ Familial partial lipodystrophy of the Dunnigan-type; 6=Hutchison-Gilford progeria syndrome.
In humans, the LMNA gene (Figure 1) codes for A-type lamins and is localized to chromosome $1 \mathrm{q} 21.2^{[25]}$. LMNA consists of 12 exons and at exon 10 alternative splicing occurs giving rise to the proteins lamin A (664 amino acids) and lamin C (572 amino acids). The first 566 amino acids (exon 1-10) of lamin A and C (lamin A/C) are identical which code for an amino terminal globular head domain, central rod domain (coil 1a, 1b, and 2), and a portion of the carboxyl terminal globular tail domain ${ }^{[17,26]}$. Mutations in the human LMNA gene encoding for lamin $\mathrm{A} / \mathrm{C}$ results in several different clinical disorders referred to as "laminopathies" ${ }^{\text {"27-35] }}$. Interestingly, certain cases of laminopathies primarily affect the heart resulting in dilated cardiomyopathy with or without conduction system disease even though lamin is found in all differentiated cells in the human body ${ }^{[27-29]}$. LMNA also encodes the protein lamin C2 found in germ cells that is encoded by an alternative first exon ${ }^{[36]}$.

B-type lamins in humans are encoded by the genes LMNB1 and LMNB2 $2^{[37]}$. LMNB1 is localized to chromosome 5q23.3$\mathrm{q} 31.1$ and encodes the protein lamin $\mathrm{B} 1^{[25,38]}$. A mutation in the LMNB1 gene has been found to result in autosomal dominant leukodystrophy ${ }^{[39]}$. LMNB2 is localized to chromosome 19 p13.3 and encodes lamin B2 and lamin B $3^{[37,40]}$. A mutation in the LMNB2 gene has been found to result in acquired partial lipodystrophy ${ }^{[41,42]}$. Currently, these are the only two disorders discovered to be associated with mutations in the B-type lamins.

\section{Laminopathies}

Almost all lamin mutations discovered to-date resulting in human disease are located within the LMNA gene. These mutations result in several different clinical disorders with various phenotypes referred to as laminopathies; there are more than 10 clinical phenotypes that can be divided into four broad categories: myopathy, neuropathy, lipodystrophy and progeria, with overlap between groups. Well over 100 mutations have been discovered in the LMNA gene with the majority resulting in cardiac involvement. Over $90 \%$ of laminopathies are due to a nucleotide substitution ${ }^{[21,43]}$.

In a large French pedigree, Bonne et al, in $1999^{[30]}$ discovered for the first time that a mutation (nonsense and missense) in the LMNA gene resulted in an inherited disorder, autosomal dominant Emery-Dreifuss muscular dystrophy (EDMD). Since that time several mutations, mostly missense, have been discovered throughout the LMNA gene resulting in EDMD. EDMD is characterized by contractures of the elbows and Achilles, muscle wasting with humeroperoneal weakness and cardiomyopathy with conduction disease. Symptoms begin within the first few years of life with difficulty ambulating. Cardiac involvement usually occurs after the onset of skeletal myopathy between the first and fourth decades of life resulting in conduction system disease (atrioventricular block; atrial and ventricular arrhythmias), dilated cardiomyopathy and sudden cardiac death ${ }^{[43,44]}$. Autosomal recessive EDMD is much less common with a few reported cases demonstrating an earlier phenotypic expression of skeletal myopathy, however, cardiac involvement has not been seen ${ }^{[45,46]}$.

Limb girdle muscular dystrophy type 1B (LGMD1B) results primarily from a missense mutation with an autosomal dominant inheritance; several missense mutations located throughout the LMNA gene resulting in LGMD1B have been identified. Affected individuals develop progressive limb 
girdle weakness with or without calf hypertrophy and dilated cardiomyopathy with conduction system disease may occur ${ }^{[47]}$. Interestingly, a single nucleotide deletion at position 959 has been identified within exon 6 of the LMNA gene in one family resulting in different phenotypic expressions within the same family including LGMD1B-like symptoms, autosomal dominant EDMD-like symptoms and isolated dilated cardiomyopathy with conduction system disease ${ }^{[48]}$.

Specific mutations in the LMNA gene can result in isolated cardiac involvement in which the affected individuals develop dilated cardiomyopathy with or without conduction system disease. Dilated cardiomyopathy is a disorder of the myocyte characterized by cardiac dilation and systolic dysfunction ${ }^{[49,50]}$. Lamin mutations are likely the most common cause of idiopathic dilated cardiomyopathies. Approximately $30 \%$ of idiopathic dilated cardiomyopathies are inherited ${ }^{[51-53]}$. Several mutations have been discovered, mostly missense mutations, located throughout the LMNA gene ${ }^{[43]}$. An example of the natural history of this disease and evolution to the discovery of one of the LMNA genetic mutations is illustrated by the immigration of a young couple from Bavaria, Germany to Maryland, United States of America and then to central Ohio in 1830. Descendants of this couple in the 1960s presented to The Ohio State University Medical Center with high-grade atrioventricular (AV) block; careful family history revealed autosomal dominant inheritance after reconstructing an extensive nine generations pedigree. Following the family members closely for several decades, it was found that affected patients between 30 to 70 years of age also developed non-ischemic dilated cardiomyopathy; sudden cardiac death may also occur. Autopsy in several cases demonstrated severe fibrosis in the sinus node, AV node, atria and ventricles. Fibrosis was more severe in the atria compared to the ventricles fibrosis. More recently, ventricular fibrosis has been seen on cardiac magnetic resonance imaging. Family wide genotyping performed in family members revealed a 2-nucleotide pair deletion in the LMNA gene (cytosine in position 906 and thymine in position 907 at exon 5) resulting in a sequence of amino acid changes beginning at position 302 and eventually leading to the amino acid substitution of cysteine for serine at position 328 forming a premature stop codon with protein truncation ${ }^{[54]}$.

Charcot-Marie Tooth (CMT) disorders are the most common group of inherited neuropathies affecting 10 to 40 per 100000 individuals. One sub-type, CMT2B1, is a sensorimotor axonal neuropathy with an autosomal recessive inheritance

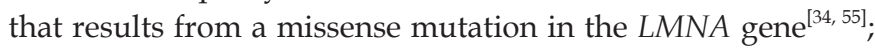
ten Algerian families with CMT2B1 have demonstrated a missense mutation resulting in the substitution of the amino acid arginine for cysteine at position 298 (R298C) ${ }^{[34,56]}$. Onset of symptoms ranges from early childhood to early adulthood with distal muscle weakness and wasting occurring in the distal extremities, more evident in the legs compared to the arms. A sensory deficit may occur in the feet and lower extremities ${ }^{[57]}$. There is one family from south France found to have an axonal neuropathy with cardiac involvement and an autosomal dominant inheritance. In this family, a missense mutation was found to result in the substitution of the amino acid glutamic acid for aspartic acid at position 33 (E33D) leading to CMT, cardiomyopathy with conduction system disease, muscular dystrophy and leuconychia ${ }^{[58]}$.

Familial partial lipodystrophy of the Dunnigan-type (FPLD) has an autosomal dominance inheritance. FPLD most commonly occurs from a missense mutation in exon 8 of the LMNA gene resulting in the substitution of the amino acid arginine for tryptophan at position 482 (R482W) that encodes primarily the carboxyl terminal globular tail domain ${ }^{[59]}$. FPLD primarily affects adipocyte cells with progressive loss of fat from the extremities and trunk with accumulation of fat in the face and neck ${ }^{[60]}$. Further, affected individuals develop metabolic abnormalities including insulin resistance and glucose intolerance. Hypertriglyceridaemia may also occur. Onset of symptoms usually occurs at puberty ${ }^{[59,61]}$.

Hutchison-Gilford progeria syndrome (HGPS) is a multisystem disorder characterized by premature aging. Majority of affected individuals with HGPS results from a de novo heterozygous single base substitution of cytosine for thymine at position 1824. This substitution results in an abnormal splice donor site in exon 11 of the LMNA gene that produces a lamin A protein lacking 50 amino acids from the carboxyl terminal globular tail domain ${ }^{[35]}$. Affected individuals demonstrate skeletal abnormalities, micrognathia, mid-face hypoplasia, alopecia, loss of subcutaneous fat and pre-mature atherosclerosis. Most affected individuals die between the first and second decades of life from cardiovascular complications ${ }^{[43]}$. HGPS has also been found to have an autosomal recessive inheritance in one consanguineous family where a missense mutation results in the amino acid substitution of lysine for asparagine at position $542(\mathrm{~K} 542 \mathrm{~N})^{[62]}$.

\section{Mechanisms underlying laminopathies}

Researchers have strived to elucidate why certain laminopathies result in specific tissue phenotypes even though lamin A/C essentially is found in all differentiated cells within the human body. In addition, different mutations have been shown to result in the same clinical phenotype. Moreover, the same single mutation can result in various phenotypic expressions ${ }^{[63]}$. Several hypotheses have been postulated to explain these observations including: structural, gene expression, cell proliferation and protein-protein interaction; however, a specific laminopathy may not be exclusive to one hypothesis.

\section{Structural hypothesis}

A mutation in the LMNA gene producing abnormal lamin weakens the nuclear envelope and develops abnormal nuclear-cytoplasmic interactions, thus decreasing the structural integrity of the cell. These changes make the cell susceptible to mechanical stress potentially leading to cell death, especially striated muscle or cardiomyocytes that are exposed to mechanical stress ${ }^{[64]}$. Embryonic fibroblasts obtained from Lmna knockout mice demonstrate the inability of the nuclear envelope to withstand physical force easily rupturing as compared to controls ${ }^{[6]]}$. Skeletal muscle biopsies obtained from 
patients with autosomal EDMD and cardiac biopsies from patients with dilated cardiomyopathies have shown physical damage to the cells including ruptured nuclear envelopes and localization of chromatin into the cytoplasm ${ }^{[66,67]}$. In addition, fibroblasts from patients with HGP have shown to have an abnormal nuclear envelope shape, clustering of nuclear pores and loss of peripheral heterochromatin that worsen as the cells $a \mathrm{e}^{[68]}$. Fibroblast from FPLD patients also revealed abnormal nuclei structure and when exposed to heat stress had an increase in cell death compared to controls ${ }^{[69]}$.

\section{Gene expression hypothesis}

Lamin plays an important role in DNA repair and replication as well as transcriptional regulation, thus abnormal lamin will affect these functions ${ }^{[18,19,70]}$. The disruption of the normal organization of lamin in mammalian cells has been shown to inhibit RNA polymerase II-dependent transcription ${ }^{[71]}$. The gene expression hypothesis may particularly provide some insight in adipocyte disorders like FPLD. Peroxisome proliferator activator receptor gamma (PPAR $\mathrm{P}$ ) and sterol regulatory element binding protein-1 (SREBP1) are two of several genes that regulate adipogenesis. SREBP1 binds to pre-lamin A and also activates PPARY. Pre-lamin A in fibroblasts from patients with FPLD has been shown to accumulate at the nuclear envelope sequestering SREBP1, thus decreasing PPARY activation and in turn inhibiting adipogenesis ${ }^{[72-75]}$. These findings may partially explain the progressive loss of fat in the extremities and trunk of individuals with FPLD. Further, deficient SREBP1 has been associated with type 2 diabetes mellitus, also seen in individuals with FPLD ${ }^{[76]}$.

\section{Cell proliferation hypothesis}

Stem cells fail to differentiate properly due to abnormal lamin within the cell. Individuals with HGPS have an increased production of progerin, a mutant form of the lamin A protein. Progerin accumulates near the nucleus altering the structure of the nuclear lamina. Studies have demonstrated that progerin interferes with the normal function of human mesenchymal stem cells (MSC) altering their ability to differentiate appropriately. MSC typically undergo differentiation to form several of the tissues affected in HGPS including bone (osteogenesis) and fat (adipogenesis); these effects are mediated by progerin activating downstream effectors of the Notch signaling pathway, a major regulator of human MSCs ${ }^{[77]}$. Further, studies have shown that the differentiation of mouse skeletal stem cells, satellite cells, is associated with the relocation of nucleoplasmic lamin $\mathrm{A} / \mathrm{C}$ to the nuclear lamina and reorganization of the nucleoskeleton; $\mathrm{C} 2 \mathrm{C} 12$ myoblasts transfected with a mutant lamin A, known to cause autosomal dominant EDMD, prevented the relocation of lamin and reorganization of the nucleoskeleton, resulting in the inhibition of myoblast differentiation $^{[78]}$.

\section{Protein-protein interaction hypothesis}

Altered lamin due to a LMNA gene mutation will develop an abnormal interaction with associated proteins resulting in disorganized cell structure and in-turn cell dysfunction ${ }^{[79-82]}$. Nikolova et al, demonstrated that in lamin A/C deficient mice the intermediate filament protein desmin, important in maintaining structural integrity of the cell, became disorganized and detached from the nuclear surface ${ }^{[79,83]}$. In addition, the inner nuclear envelope proteins nesprin and emerin, both important in maintaining cell structure, mis-localized to the endoplasmic reticulum in SW-13 cells which lack lamin A and re-localized to the inner nuclear envelope in SW 13/20 cells that contain lamin $\mathrm{A}^{[80]}$. Cardiomyocytes of LMNA knockout mice demonstrated an altered nuclear envelope, disorganization of nesprin- 1 and changes in the expression and distribution of nuclear and cytoskeletal actin ${ }^{[8]}$. Studies by Raharjo $e t$ $a l^{[82]}$, showed that point mutations in lamin A/C resulting in the substitution of amino acids leucine for arginine at position 85 (L85R) and asparagine for lysine at position 195 (N195K), both known to cause dilated cardiomyopathy, altered the assembly of lamin A/C resulting in the partial mis-localization of emerin in HeLa cells; these findings were also seen in the point mutation resulting in the substitution of amino acid leucine for proline at position 530 (L530P), known to cause autosomal dominant $\mathrm{EDMD}^{[82]}$. Further, eliminating lamin A/ $\mathrm{C}$ from the nuclear envelope of HeLa cells resulted in emerin mis-localization and the formation of aggregates within the endoplasmic reticulum ${ }^{[81]}$.

\section{Conclusions and perspectives}

Lamins are intermediate filament proteins and are major components of the nuclear lamina playing an important role in cell regulation and structural integrity ${ }^{[14-17]}$. There are well over 100 mutations in the LMNA gene, encoding for the protein lamin $\mathrm{A} / \mathrm{C}$, that result in more than 10 clinical disorders collectively referred to as laminopathies ${ }^{[37,43]}$. The challenge remains to determine why certain LMNA mutations result in tissue specific diseases, even though lamin $\mathrm{A} / \mathrm{C}$ is found in all differentiated cells in the human body.

The laminopathy story is an elegant example of the importance of close collaboration that must exist between the physician-scientist and basic research-scientist in the study of heritable disorders. Careful physical examination of affected individuals and meticulous investigation of their family history allows the physician-scientist to understand the complexity of the disease, while the basic research-scientist helps in defining molecular mechanisms of that disease. Animal models, including Lmna knockout mice and mice carrying various LMNA missense mutations, have provided much insight into the mechanisms of laminopathies ${ }^{[85-87]}$. Knowledge gained from the clinic and bench will help to better understand the underlying mechanisms, and will result in therapeutic strategies to treat affected individuals and provide insight into molecular mechanisms of other human diseases.

\section{Acknowledgements}

This work was supported by NIH (HL084583, HL083422 to PJM), Pew Scholars Trust (PJM), and Fondation Leducq Award (Alliance for Calmodulin Kinase Signaling in Heart 
Disease (PJM).

\section{References}

1 Bhasin N, Cunha SR, Mudannayake M, Gigena MS, Rogers TB, Mohler PJ. Molecular basis for PP2A regulatory subunit B56\{alpha\} targeting in cardiomyocytes. Am J Physiol Heart Circ Physiol 2007; 293: H10919.

2 Le Scouarnec S, Bhasin N, Vieyres C, Hund TJ, Cunha SR, Koval O, et al. Dysfunction in ankyrin-B-dependent ion channel and transporter targeting causes human sinus node disease. Proc Natl Acad Sci U S A 2008; 105: 15617-22.

3 Mohler PJ, Le Scouarnec S, Denjoy I, Lowe JS, Guicheney P, Caron L, et al. Defining the cellular phenotype of "ankyrin-B syndrome" variants: human ANK2 variants associated with clinical phenotypes display a spectrum of activities in cardiomyocytes. Circulation 2007; 115 : 432-41.

4 Mohler PJ, Schott JJ, Gramolini AO, Dilly KW, Guatimosim S, duBell WH, et al. Ankyrin-B mutation causes type 4 long-QT cardiac arrhythmia and sudden cardiac death. Nature 2003; 421: 634-9.

5 Mohler PJ, Splawski I, Napolitano C, Bottelli G, Sharpe L, Timothy K, et al. A cardiac arrhythmia syndrome caused by loss of ankyrin-B function. Proc Natl Acad Sci U S A 2004; 101: 9137-42.

6 Hund TJ, Koval O, Li J, Wright PJ, Qian L, Snyder JS, et al. A betalV spectrin/CaMKII signaling complex is essential for vertebrate membrane excitability in mice. J Clin Invest 2010; 120: 3508-19.

7 Lowe JS, Palygin O, Bhasin N, Hund TJ, Boyden PA, Shibata E, et al. Voltage-gated Nav channel targeting in the heart requires an ankyrin-G dependent cellular pathway. J Cell Biol 2008; 180: 173-86.

8 Mohler PJ, Rivolta I, Napolitano C, Lemaillet G, Lambert S, Priori SG, et al. Nav1.5 E1053K mutation causing Brugada syndrome blocks binding to ankyrin-G and expression of Nav1.5 on the surface of cardiomyocytes. Proc Natl Acad Sci U S A 2004; 101: 17533-8.

9 Ueda K, Valdivia C, Medeiros-Domingo A, Tester DJ, Vatta M, Farrugia G, et al. Syntrophin mutation associated with long QT syndrome through activation of the nNOS-SCN5A macromolecular complex. Proc Natl Acad Sci U S A 2008; 105: 9355-60.

10 Vatta M, Ackerman MJ, Ye B, Makielski JC, Ughanze EE, Taylor EW, et al. Mutant caveolin-3 induces persistent late sodium current and is associated with long-QT syndrome. Circulation 2006; 114: 2104-12.

11 Piippo K, Swan H, Pasternack M, Chapman H, Paavonen K, Viitasalo $M$, et al. A founder mutation of the potassium channel KCNQ1 in long QT syndrome: implications for estimation of disease prevalence and molecular diagnostics. J Am Coll Cardiol 2001; 37: 562-8.

12 Chen L, Marquardt ML, Tester DJ, Sampson KJ, Ackerman MJ, Kass RS. Mutation of an A-kinase-anchoring protein causes long-QT syndrome. Proc Natl Acad Sci U S A 2007; 104: 20990-5.

13 London B, Michalec M, Mehdi H, Zhu X, Kerchner L, Sanyal S, et al. Mutation in glycerol-3-phosphate dehydrogenase 1 like gene (GPD1-L) decreases cardiac $\mathrm{Na}^{+}$current and causes inherited arrhythmias. Circulation 2007; 116: 2260-8.

14 Aebi U, Cohn J, Buhle L, Gerace L. The nuclear lamina is a meshwork of intermediate-type filaments. Nature 1986; 323: 560-4.

15 Hutchison CJ. Lamins: building blocks or regulators of gene expression? Nat Rev Mol Cell Biol 2002; 3: 848-58.

16 Mattout-Drubezki A, Gruenbaum Y. Dynamic interactions of nuclear lamina proteins with chromatin and transcriptional machinery. Cell Mol Life Sci 2003; 60: 2053-63.

17 Stuurman N, Heins S, Aebi U. Nuclear lamins: their structure, assembly, and interactions. J Struct Biol 1998; 122: 42-66.

18 Dechat T, Pfleghaar K, Sengupta K, Shimi T, Shumaker DK, Solimando $L$, et al. Nuclear lamins: major factors in the structural organization and function of the nucleus and chromatin. Genes Dev 2008; 22: 832-53.

19 Prokocimer M, Davidovich M, Nissim-Rafinia M, Wiesel-Motiuk N, Bar DZ, Barkan R, et al. Nuclear lamins: key regulators of nuclear structure and activities. J Cell Mol Med 2009; 13: 1059-85.

20 Foster CR, Przyborski SA, Wilson RG, Hutchison CJ. Lamins as cancer biomarkers. Biochem Soc Trans 2010; 38: 297-300.

21 Zaremba-Czogalla M, Dubinska-Magiera M, Rzepecki R. Laminopathies: the molecular background of the disease and the prospects for its treatment. Cell Mol Biol Lett 2011; 16: 114-48.

22 Krohne G, Benavente R. The nuclear lamins. A multigene family of proteins in evolution and differentiation. Exp Cell Res 1986; 162: $1-10$.

23 Gerace L, Blobel G. The nuclear envelope lamina is reversibly depolymerized during mitosis. Cell 1980; 19: 277-87.

24 Herrmann H, Bar H, Kreplak L, Strelkov SV, Aebi U. Intermediate filaments: from cell architecture to nanomechanics. Nat Rev Mol Cell Biol 2007; 8: 562-73.

25 Wydner KL, McNeil JA, Lin F, Worman HJ, Lawrence JB. Chromosomal assignment of human nuclear envelope protein genes LMNA, LMNB1, and LBR by fluorescence in situ hybridization. Genomics 1996; 32 : 474-8.

26 Lin F, Worman HJ. Structural organization of the human gene encoding nuclear lamin A and nuclear lamin C. J Biol Chem 1993; 268: 16321-6.

27 Kass S, MacRae C, Graber HL, Sparks EA, McNamara D, Boudoulas $\mathrm{H}$, et al. A gene defect that causes conduction system disease and dilated cardiomyopathy maps to chromosome 1p1-1q1. Nat Genet 1994; 7: 546-51.

28 Taylor MR, Fain PR, Sinagra G, Robinson ML, Robertson AD, Carniel E, et al. Natural history of dilated cardiomyopathy due to lamin $\mathrm{A} / \mathrm{C}$ gene mutations. J Am Coll Cardiol 2003; 41: 771-80.

29 Fatkin D, MacRae C, Sasaki T, Wolff MR, Porcu M, Frenneaux M, et al. Missense mutations in the rod domain of the lamin $\mathrm{A} / \mathrm{C}$ gene as causes of dilated cardiomyopathy and conduction-system disease. $\mathrm{N}$ Engl J Med 1999; 341: 1715-24.

30 Bonne G, Di Barletta MR, Varnous S, Becane HM, Hammouda EH, Merlini L, et al. Mutations in the gene encoding lamin A/C cause autosomal dominant Emery-Dreifuss muscular dystrophy. Nat Genet 1999; 21: 285-8.

31 di Barletta MR, Viatchenko-Karpinski S, Nori A, Memmi M, Terentyev $D$, Turcato $F$, et al. Clinical phenotype and functional characterization of CASQ2 mutations associated with catecholaminergic polymorphic ventricular tachycardia. Circulation 2006; 114: 1012-9.

32 Muchir A, Bonne G, van der Kooi AJ, van Meegen M, Baas F, Bolhuis $\mathrm{PA}$, et al. Identification of mutations in the gene encoding lamins $\mathrm{A} / \mathrm{C}$ in autosomal dominant limb girdle muscular dystrophy with atrioventricular conduction disturbances (LGMD1B). Hum Mol Genet 2000; 9: 1453-9.

33 Shackleton S, Lloyd DJ, Jackson SN, Evans R, Niermeijer MF, Singh $\mathrm{BM}$, et al. LMNA, encoding lamin A/C, is mutated in partial lipodystrophy. Nat Genet 2000; 24: 153-6.

34 De Sandre-Giovannoli A, Chaouch M, Kozlov S, Vallat JM, Tazir M, Kassouri N, et al. Homozygous defects in LMNA, encoding lamin A/C nuclear-envelope proteins, cause autosomal recessive axonal neuropathy in human (Charcot-Marie-Tooth disorder type 2) and mouse. Am J Hum Genet 2002; 70: 726-36.

35 Eriksson M, Brown WT, Gordon LB, Glynn MW, Singer J, Scott L, et al. Recurrent de novo point mutations in lamin A cause HutchinsonGilford progeria syndrome [Research Support, Non-US Gov't]. Nature 2003; 423: 293-8. 
36 Furukawa $\mathrm{K}$, Inagaki $\mathrm{H}$, Hotta Y. Identification and cloning of an mRNA coding for a germ cell-specific A-type lamin in mice. Exp Cell Res 1994; 212: 426-30.

37 Worman HJ, Bonne G. "Laminopathies": a wide spectrum of human disease. Exp Cell Res 2007; 313: 2121-33.

38 Lin F, Worman HJ. Structural organization of the human gene (LMNB1) encoding nuclear lamin B1. Genomics 1995; 27: 230-6.

39 Padiath QS, Saigoh K, Schiffmann R, Asahara H, Yamada T, Koeppen A, et al. Lamin B1 duplications cause autosomal dominant leukodystrophy. Nat Genet 2006; 38: 1114-23.

40 Furukawa K, Hotta Y. cDNA cloning of a germ cell specific lamin B3 from mouse spermatocytes and analysis of its function by ectopic expression in somatic cells. EMBO J 1993; 12: 97-106.

41 Hegele RA, Cao H, Liu DM, Costain GA, Charlton-Menys V, Rodger NW, et al. Sequencing of the reannotated LMNB2 gene reveals novel mutations in patients with acquired partial lipodystrophy. Am J Hum Genet 2006; 79: 383-9.

42 Hegele RA, Oshima J. Phenomics and lamins: from disease to therapy. Exp Cell Res 2007; 313: 2134-43.

43 Rankin J, Ellard S. The laminopathies: a clinical review. Clin Genet 2006; 70: 261-74.

44 Emery AE. The muscular dystrophies. Lancet 2002; 359: 687-95.

45 Sanna T, Dello Russo A, Toniolo D, Vytopil M, Pelargonio G, De Martino $\mathrm{G}$, et al. Cardiac features of Emery-Dreifuss muscular dystrophy caused by lamin A/C gene mutations. Eur Heart J 2003; 24: $2227-$ 36.

46 Raffaele Di Barletta M, Ricci E, Galluzzi G, Tonali P, Mora M, Morandi $\mathrm{L}$, et al. Different mutations in the LMNA gene cause autosomal dominant and autosomal recessive Emery-Dreifuss muscular dystrophy. Am J Human Genet 2000; 66: 1407-12.

47 Bushby KM. The limb-girdle muscular dystrophies-multiple genes, multiple mechanisms. Hum Mol Genet 1999; 8: 1875-82.

48 Brodsky GL, Muntoni F, Miocic S, Sinagra G, Sewry C, Mestroni L. Lamin A/C gene mutation associated with dilated cardiomyopathy with variable skeletal muscle involvement. Circulation 2000; 101 : 473-6.

49 Kasper EK, Agema WR, Hutchins GM, Deckers JW, Hare JM, Baughman KL. The causes of dilated cardiomyopathy: a clinicopathologic review of 673 consecutive patients. J Am Coll Cardiol 1994; 23 : 586-90.

50 Fatkin D, Graham RM. Molecular mechanisms of inherited cardiomyopathies. Physiol Rev 2002; 82: 945-80.

51 Michels VV, Moll PP, Miller FA, Tajik AJ, Chu JS, Driscoll DJ, et al. The frequency of familial dilated cardiomyopathy in a series of patients with idiopathic dilated cardiomyopathy. New Engl J Med 1992; 326: 77-82.

52 Grunig E, Tasman JA, Kucherer H, Franz W, Kubler W, Katus HA. Frequency and phenotypes of familial dilated cardiomyopathy. J Am Coll Cardiol 1998; 31: 186-94.

53 Keeling PJ, Gang Y, Smith G, Seo H, Bent SE, Murday V, et al. Familial dilated cardiomyopathy in the United Kingdom. Br Heart J 1995; 73 : 417-21.

54 Sparks EA, Boudoulas KD, Raman SV, Sasaki T, Graber HL, Seidman $\mathrm{CE}$, et al. Heritable cardiac conduction and myocardial disease: from the clinic to the laboratory and from the laboratory back to the clinic. Cardiology 2011; In Press.

55 Pareyson D, Marchesi C. Diagnosis, natural history, and management of Charcot-Marie-Tooth disease. Lancet Neurol 2009; 8: 654-67.

56 Tazir M, Azzedine H, Assami S, Sindou P, Nouioua S, Zemmouri R, et al. Phenotypic variability in autosomal recessive axonal CharcotMarie-Tooth disease due to the R298C mutation in lamin A/C. Brain
2004; 127: 154-63.

57 Bienfait HM, Baas F, Koelman JH, de Haan RJ, van Engelen BG, Gabreels-Festen AA, et al. Phenotype of Charcot-Marie-Tooth disease type 2. Neurology 2007; 68: 1658-67.

58 Goizet C, Yaou RB, Demay L, Richard P, Bouillot S, Rouanet M, et al. A new mutation of the lamin $\mathrm{A} / \mathrm{C}$ gene leading to autosomal dominant axonal neuropathy, muscular dystrophy, cardiac disease, and leuconychia. J Med Genet 2004; 41: e29.

59 Vantyghem MC, Pigny P, Maurage CA, Rouaix-Emery N, Stojkovic T, Cuisset JM, et al. Patients with familial partial lipodystrophy of the Dunnigan type due to a LMNA R482W mutation show muscular and cardiac abnormalities. J Clin Endocrinol Metab 2004; 89: 5337-46.

60 Garg A, Peshock RM, Fleckenstein JL. Adipose tissue distribution pattern in patients with familial partial lipodystrophy (Dunnigan variety). J Clin Endocrinol Metab 1999; 84: 170-4.

61 Speckman RA, Garg A, Du F, Bennett L, Veile R, Arioglu E, et al. Mutational and haplotype analyses of families with familial partial lipodystrophy (Dunnigan variety) reveal recurrent missense mutations in the globular C-terminal domain of lamin A/C. Am J Hum Genet 2000; 66: 1192-8.

62 Plasilova M, Chattopadhyay C, Pal P, Schaub NA, Buechner SA, Mueller $\mathrm{H}$, et al. Homozygous missense mutation in the lamin $\mathrm{A} / \mathrm{C}$ gene causes autosomal recessive Hutchinson-Gilford progeria syndrome. J Med Genet 2004; 41: 609-14.

63 Scharner J, Gnocchi VF, Ellis JA, Zammit PS. Genotype-phenotype correlations in laminopathies: how does fate translate? Biochem Soc Trans 2010; 38: 257-62.

64 Broers JL, Ramaekers FC, Bonne G, Yaou RB, Hutchison CJ. Nuclear lamins: laminopathies and their role in premature ageing. Physiol Rev 2006; 86: 967-1008.

65 Broers JL, Peeters EA, Kuijpers HJ, Endert J, Bouten CV, Oomens CW, et al. Decreased mechanical stiffness in LMNA-/- cells is caused by defective nucleo-cytoskeletal integrity: implications for the development of laminopathies. Hum Mol Genet 2004; 13: 2567-80.

66 Fidzianska A, Hausmanowa-Petrusewicz I. Architectural abnormalities in muscle nuclei. Ultrastructural differences between X-linked and autosomal dominant forms of EDMD. J Neurol Sci 2003; 210: 47-51.

67 Arbustini E, Pilotto A, Repetto A, Grasso M, Negri A, Diegoli M, et al. Autosomal dominant dilated cardiomyopathy with atrioventricular block: a lamin A/C defect-related disease. J Am Coll Cardiol 2002; 39: 981-90.

68 Goldman RD, Shumaker DK, Erdos MR, Eriksson M, Goldman AE, Gordon LB, et al. Accumulation of mutant lamin A causes progressive changes in nuclear architecture in Hutchinson-Gilford progeria syndrome. Proc Natl Acad Sci U S A 2004; 101: 8963-8.

69 Vigouroux C, Auclair M, Dubosclard E, Pouchelet M, Capeau J, Courvalin JC, et al. Nuclear envelope disorganization in fibroblasts from lipodystrophic patients with heterozygous R482Q/W mutations in the lamin A/C gene. J Cell Sci 2001; 114: 4459-68.

70 Bridger JM, Foeger N, Kill IR, Herrmann H. The nuclear lamina. Both a structural framework and a platform for genome organization. FEBS J 2007; 274: 1354-61.

71 Spann TP, Goldman AE, Wang C, Huang S, Goldman RD. Alteration of nuclear lamin organization inhibits RNA polymerase II-dependent transcription. J Cell Biol 2002; 156: 603-8.

72 Akerblad P, Mansson R, Lagergren A, Westerlund S, Basta B, Lind U, et al. Gene expression analysis suggests that EBF-1 and PPARgamma2 induce adipogenesis of NIH-3T3 cells with similar efficiency and kinetics. Physiol Genomics 2005; 23: 206-16.

$73 \mathrm{Kim} \mathrm{JB}$, Spiegelman BM. ADD1/SREBP1 promotes adipocyte differentiation and gene expression linked to fatty acid metabolism. 
Genes Dev 1996; 10: 1096-107.

74 Lloyd DJ, Trembath RC, Shackleton S. A novel interaction between lamin A and SREBP1: implications for partial lipodystrophy and other laminopathies. Hum Mol Genet 2002; 11: 769-77.

75 Capanni C, Mattioli E, Columbaro M, Lucarelli E, Parnaik VK, Novelli G, et al. Altered pre-lamin A processing is a common mechanism leading to lipodystrophy. Hum Mol Genet 2005; 14: 1489-502.

76 Sewter C, Berger D, Considine RV, Medina G, Rochford J, Ciaraldi $\mathrm{T}$, et al. Human obesity and type 2 diabetes are associated with alterations in SREBP1 isoform expression that are reproduced ex vivo by tumor necrosis factor-alpha. Diabetes 2002; 51: 1035-41.

77 Scaffidi P, Misteli T. Lamin A-dependent misregulation of adult stem cells associated with accelerated ageing. Nat Cell Biol 2008; 10: 452-9.

78 Markiewicz E, Ledran M, Hutchison CJ. Remodelling of the nuclear lamina and nucleoskeleton is required for skeletal muscle differentiation in vitro. J Cell Sci 2005; 118: 409-20.

79 Nikolova V, Leimena C, McMahon AC, Tan JC, Chandar S, Jogia D, et al. Defects in nuclear structure and function promote dilated cardiomyopathy in lamin A/C-deficient mice. J Clin Invest 2004; 113: 357 69.

80 Zhang Q, Ragnauth CD, Skepper JN, Worth NF, Warren DT, Roberts RG, et al. Nesprin-2 is a multi-isomeric protein that binds lamin and emerin at the nuclear envelope and forms a subcellular network in skeletal muscle. J Cell Sci 2005; 118: 673-87.
81 Vaughan A, Alvarez-Reyes M, Bridger JM, Broers JL, Ramaekers FC, Wehnert $\mathrm{M}$, et al. Both emerin and lamin $\mathrm{C}$ depend on lamin A for localization at the nuclear envelope. J Cell Sci 2001; 114: 2577-90.

82 Raharjo WH, Enarson P, Sullivan T, Stewart CL, Burke B. Nuclear envelope defects associated with LMNA mutations cause dilated cardiomyopathy and Emery-Dreifuss muscular dystrophy. J Cell Sci 2001; 114: 4447-57.

83 Paulin D, Li Z. Desmin: a major intermediate filament protein essential for the structural integrity and function of muscle. Exp Cell Res 2004; 301: 1-7.

84 Nikolova-Krstevski V, Leimena C, Xiao XH, Kesteven S, Tan JC, Yeo LS, et al. Nesprin-1 and actin contribute to nuclear and cytoskeletal defects in lamin A/C-deficient cardiomyopathy. J Mol Cell Cardiol 2011; 50: 479-86.

85 Sullivan T, Escalante-Alcalde D, Bhatt H, Anver M, Bhat N, Nagashima $\mathrm{K}$, et al. Loss of A-type lamin expression compromises nuclear envelope integrity leading to muscular dystrophy. J Cell Biol 1999; 147: 913-20.

86 Mounkes LC, Kozlov SV, Rottman JN, Stewart CL. Expression of an LMNA-N195K variant of A-type lamins results in cardiac conduction defects and death in mice. Hum Mol Genet 2005; 14: 2167-80.

87 Wang Y, Herron AJ, Worman HJ. Pathology and nuclear abnormalities in hearts of transgenic mice expressing M371K lamin A encoded by an LMNA mutation causing Emery-Dreifuss muscular dystrophy. Hum Mol Genet 2006; 15: 2479-89. 